\title{
Patients' satisfaction with the bulk trolley system in a government hospital in Malaysia.
}

\begin{abstract}
Purpose: The purpose of this paper is to determine patients' satisfaction with the bulk trolley food service system and the effect of the system on energy and protein intakes. Design/methodology/approach: An interview-based questionnaire was used to measure patients' satisfaction $(n=70)$ with the hospital food services. Dietary intake of hospital food was determined through one-day weighed food intake survey and a food record for nonhospital food. Findings: The majority of the patients (98.6 per cent) were satisfied and 1.4 per cent was very satisfied with the food service. Energy (kcal) and protein (g) intakes from hospital food were higher than that of outside food $(p<0.05)$. However, most patients did not obtain their full energy and protein requirements from the hospital food provided. Four food service dimensions were found to be significantly correlated with patients' overall satisfaction ( $\mathrm{p}<0.05)$. Research limitations/implications: The questionnaire was adapted from the study by Capra et al. and modified to suit the local food service system, thus the application may be context-specific. The instrument did not measure factors that influence hospital food consumption, nor did it differentiate between the acceptability of different kinds of food. Also a comparison of patients' acceptance between the plated and bulk trolley system was not conducted in this study. Practical implications: The results of the study can be used as a basis for decision making and for future planning of the food service system. The findings prompt analytical comparison, between the bulk trolley, and plated systems, in determining patients' preference, and to increase food intake. Originality/value: Patient satisfaction surveys are regularly conducted in the country but none had ever studied the effectiveness of the bulk trolley system in relation to patients' satisfaction. The findings are noteworthy and, compared with the past literature review, the difference in the way the system is carried out in the country may be the contributing factor regarding patients' satisfaction system.
\end{abstract}

Keyword: Customer satisfaction; Hospitals; Malaysia; Patient trolleys; Patients. 